\title{
Influence of the Trochoidal Tool Path Generation Method on the Milling Process Efficiency
}

\author{
Kamil Waszczuk ${ }^{1}$ \\ 1 Wroclaw University of Technology and Science, Faculty of Mechanical Engineering, Łukasiewicza 5, 50-370 \\ Wrocław, Poland \\ e-mail: kamil.waszczuk@pwr.edu.pl
}

\begin{abstract}
The article presents a comparison of three trochoidal paths: written by G-Code, generated using the overlays from the machine level, and generated using the CAD/CAM environment. The parameters determining the effectiveness of the process were: maximum achievable feed speed, surface roughness and waviness, cutting forces and cutting temperature when milling NC6 steel (50HRC) using a $10 \mathrm{~mm}$ cutter dimeter. The main measurement results include: an increase in the maximum feed speed value by almost $35 \%$ when using the A and $\mathrm{C}$ paths compared to the type B path and nearly a double increase in surface roughness when using the path generated using the $\mathrm{CAD} / \mathrm{CAM}$ environment compared to the $\mathrm{B}$ path. The most important conclusions was that it is not always possible to machine with the recommended parameters by the tool manufacturer, especially when machining narrow grooves. It was proven that that the use of paths with the displacement described by arcs and straight lines as a trochoidal step over reduces the possibility of milling at high feed rate.
\end{abstract}

Keywords: trochoidal milling, hard machining, slot milling, tool path, trochoidal step over.

\section{INTRODUCTION}

Trochoidal milling is defined as a circular milling with simultaneous forward movements (example of the generated of tool path - Fig. 1) [14].

Trochoidal milling belongs to high-speed machining (HSM). The low angle of the tool wrap allows reducing the cutting forces up to $70 \%$, compared to conventional milling, where it is $180^{\circ}$ [10]. This allows the use of larger depths of cut (often $1 \div 2 \times$ tool diameter) and a significant increase in the cutting speed. More information on trochoidal milling is provided in the articles $[14,15,17]$.

The main problems of trochoidal machining include: difficulty in interpreting the G-Code in the milling machine iTNC controller, frequent lack of overlays in the controller software for generating the trochoid milling cycle, limited acceleration options in the $\mathrm{X}$ and $\mathrm{Y}$ axes resulting in a significant reduction in the feed speed.

The mentioned problems are not yet sufficiently resolved $[1-13,16,18]$ or there are no articles solving these problems. The authors of the articles focused mainly on the possibilities of trochoidal milling, or on the effects obtained with trochoidal milling using paths generated only by the CAM environment. Therefore, this paper compares path generation using $\mathrm{G}$ code (path A), generated using overlays from the machine level (path B) and the CAD/CAM - NX Siemens environment (path $\mathrm{C}$ ) as a supplement to the current state of knowledge. Different methods of generating the trochoidal paths allow visualizing the factors determining the final effect of milling.

\section{TROCHOIDAL TOOL PATHS}

Trochoidal paths were generated in three ways:

- A - quasi-trochoid (Fig. 2): described by movement circle (G-Code),

- B-stretched quasi-trochoid (Fig. 3): described by arcs and straight lines (iTNC driver), 


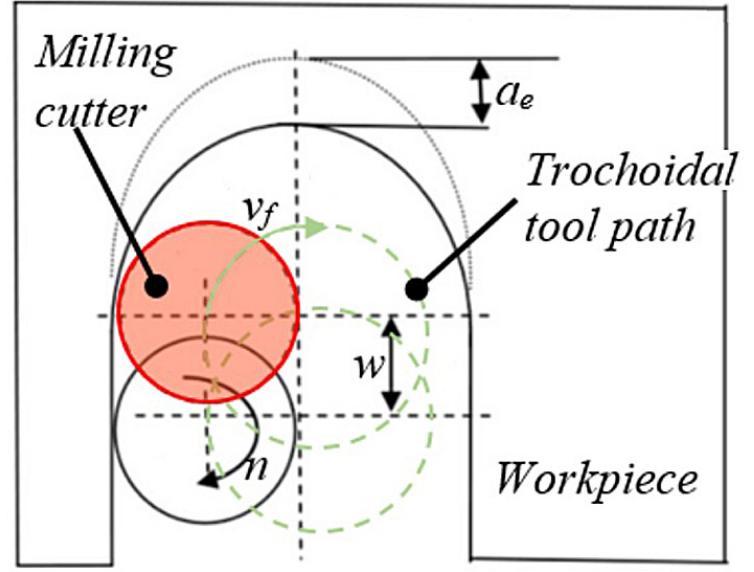

Fig. 1. An example of generated tool path, where: $w$ - trochoid step over, $a_{e}-$ width of cut, $v_{f}$ - feed speed, $n$ - rotation speed

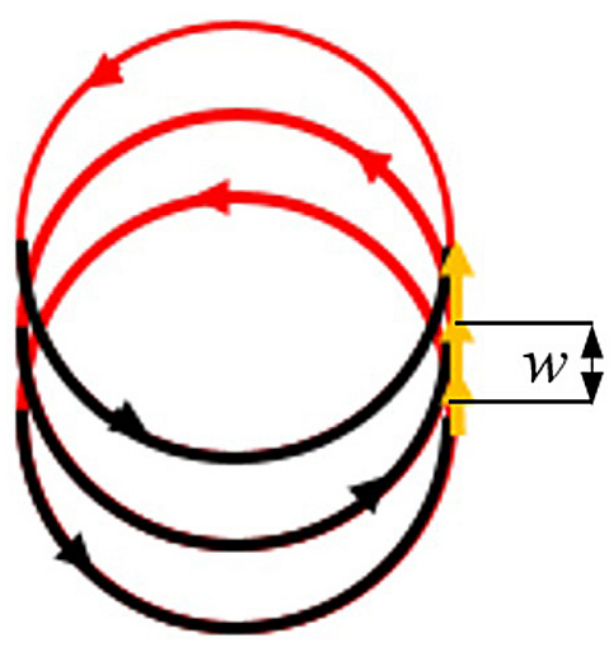

Fig. 2. Trochoidal tool path A type; $w$ - step over

- C - point by point quasi-trochoid (Fig. 4): described by short lines between a lot of points (CAD/CAM).

Type A - quasi-trochoid. The path was generated as shifts centres of the circles. During programming, the $\mathrm{CC}$ command - circle centre coordinates and $\mathrm{C}$ functions - circle end coordinates were used. The step over $(w)$ was a straight line on one of the walls of the groove being made.

Type B - the path was generated as a displacement of successive arches and straight lines. There was a straight line between the arches to obtain similar side walls of the groove. The path generated from the milling machine's iTNC driver.

Type C path - is a path commonly used in the CAM environment. It is generated as shifts

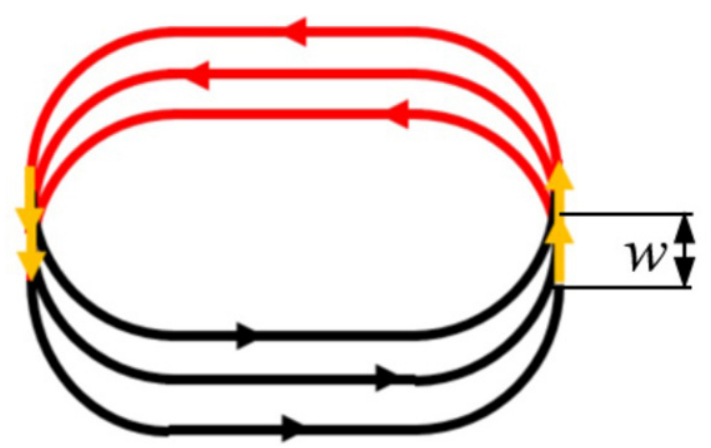

Fig. 3. Trochoidal tool path B type; w-step over

of successive points by a fixed value, relative to each other. The step over $(w)$ of the trochoid occurs as a shift of subsequent ones points form.

\section{TROCHOIDAL TOOL PATH EFFICIENCY}

In the article, the trochoidal paths of type: $\mathrm{A}, \mathrm{B}$ and $\mathrm{C}$ were tested. The choice of paths was conditioned by preliminary studies in which the stability of the milling process was determined. During the research on the impact of trochoidal path geometry on the obtainable maximum values of feed speed, the $12,14,16,22,28,32,36$, and $40 \mathrm{~mm}$ wide grooves were milled. The parameters used for trochoidal milling are the ones recommended by the manufacturer of tools for machining NC6 grade steel with a hardness of 50 HRC. They were: $f_{z}=0.06 \mathrm{~mm}, v_{c}=150 \mathrm{~m} / \mathrm{min}$, $w=0.4 \mathrm{~mm}, v_{f}=2000 \mathrm{~mm} / \mathrm{min}, a_{p}=10 \mathrm{~mm}$. For the groove width, the maximum achievable feed speed $v_{f}[\mathrm{~mm} / \mathrm{min}]$ (relative to the tool axis) was recorded at a constant value of feed per tooth: $f_{z}$ $=0.06 \mathrm{~mm}$. The maximum achievable feed speed was defined as the stable value read from the machine level when the iTNC driver does not reduce

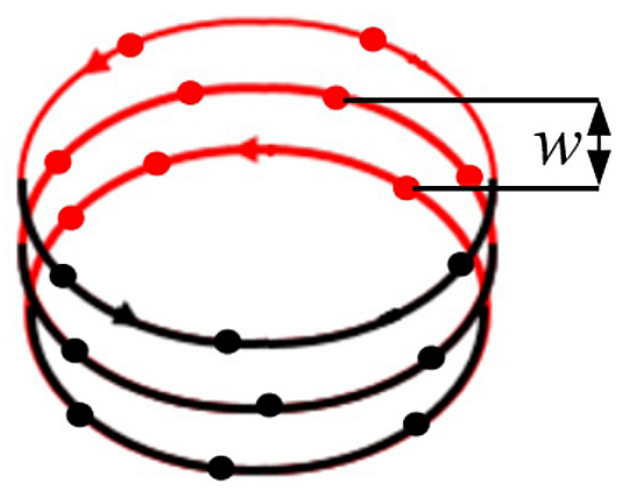

Fig. 4. Trochoidal tool path B type; w - step over 


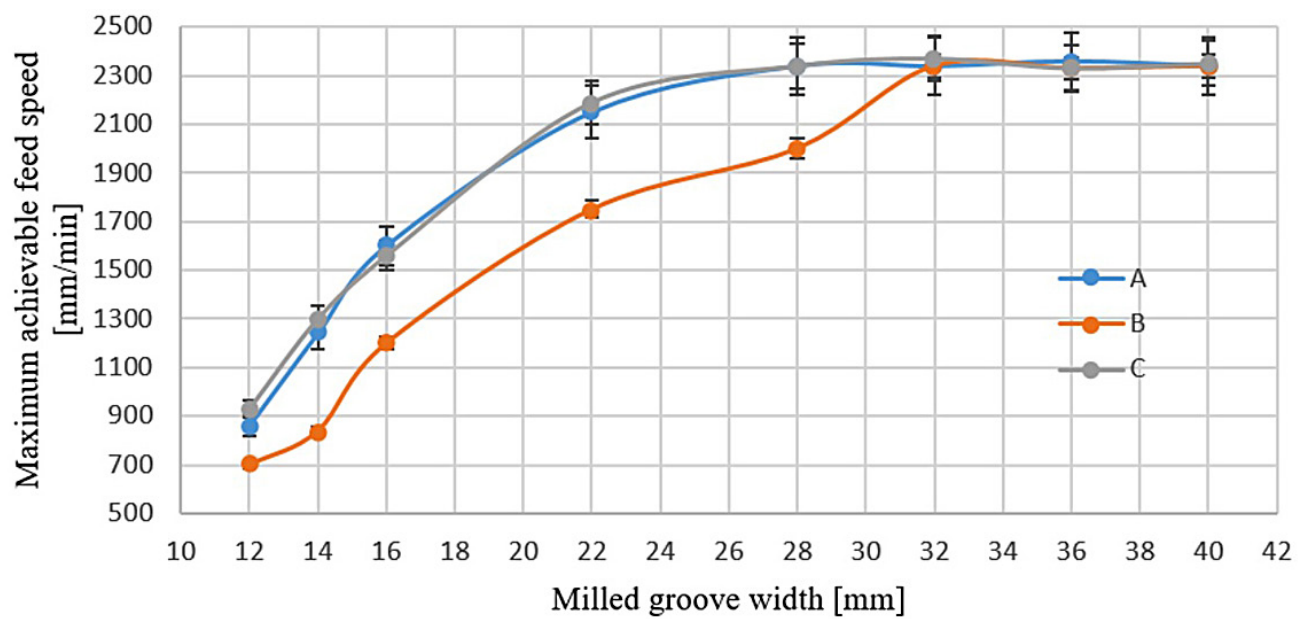

Fig. 5. Influence of the milled groove width on the maximum achievable feed speed, where: A, B, C - trochoidal tool paths

the programmed feed automatically for the imposed tolerance field $T=0.08 \mathrm{~mm}$ (in accordance with 32 DIN / ISO: G62 cycle tolerance) [3].

A summary of the research results regarding the impact of the trochoidal path geometry on the possible feed speeds for the Heidenhain iTNC530 control for the Hermle $300 \mathrm{u}$ milling machine is shown in Figure 5.

The maximum possible feed speed using paths type $\mathrm{A}$ and $\mathrm{C}$ was similar. The differences between the path programmed manually and with the CAM environment were up to about $8 \%$. The lowest maximum feed speeds were obtained with the type B trochoidal path. The values of the feed speed were lower within $15-35 \%$ than the other paths. Above the groove width $32 \mathrm{~mm}$, the values of the feed speed for all tested trochoidal paths stabilized at the level of about $2340 \mathrm{~mm} / \mathrm{min}(+/-$ $2 \%$ ). The dispersion of results during the tests was the lowest using the B path and was about 3\%.

\section{COMPARISON OF THE EFFECTS OF THE PATHS USED}

The comparative studies of the trochoidal tool paths were carried out under the following conditions. Constant parameters: $f_{z}=0.06 \mathrm{~mm},\left(v_{f}=\right.$ $2000 \mathrm{~mm} / \mathrm{min}), v_{c}=150 \mathrm{~m} / \mathrm{min}, w=04 \mathrm{~mm}, a_{p}=$ $10 \mathrm{~mm}$. Milled grooves with dimensions: $32 \mathrm{~mm}$ width, $10 \mathrm{~mm}$ depth, $20 \mathrm{~mm}$ long in 50HRC NC6 steel. The geometric dimensions of the grooves made allowed analyzing the machined surfaces, cutting forces and record the cutting temperature. Experimental setup showed in the Figure 6.
The geometrical surface structure (Ra, Rt, Wa, Wt) was measured on a Taylor Hobson model Talysurf $120 \mathrm{~L}$ profilographometer. This device was characterized by measurement resolution $16 \mathrm{~nm}$, measuring length in the horizontal orientation $200 \mathrm{~mm}$, straightness error 0.5 $\mu \mathrm{m}$ on each measured section of $120 \mathrm{~mm}$. A measuring needle with a $90^{\circ}$ point angle and a rounding radius of $2 \mu \mathrm{m}$ was used to measure the roughness $\mathrm{Ra}$ and the waviness Wa. The traverse length was $10 \mathrm{~mm}$, cut-off lengths $0.8 \mathrm{~mm}$, measuring range $20 \mu \mathrm{m}$, feed rate of the measuring needle $0.5 \mathrm{~mm} / \mathrm{s}$. The axial cutting forces $\left(\mathrm{F}_{\mathrm{x}}, \mathrm{F}_{\mathrm{y}}, \mathrm{F}_{\mathrm{z}}\right)$ in the process were measured using a Kistelr model 9129AA piezoelectric force meter, a Kistelr model 5070A amplifier, Kistler model

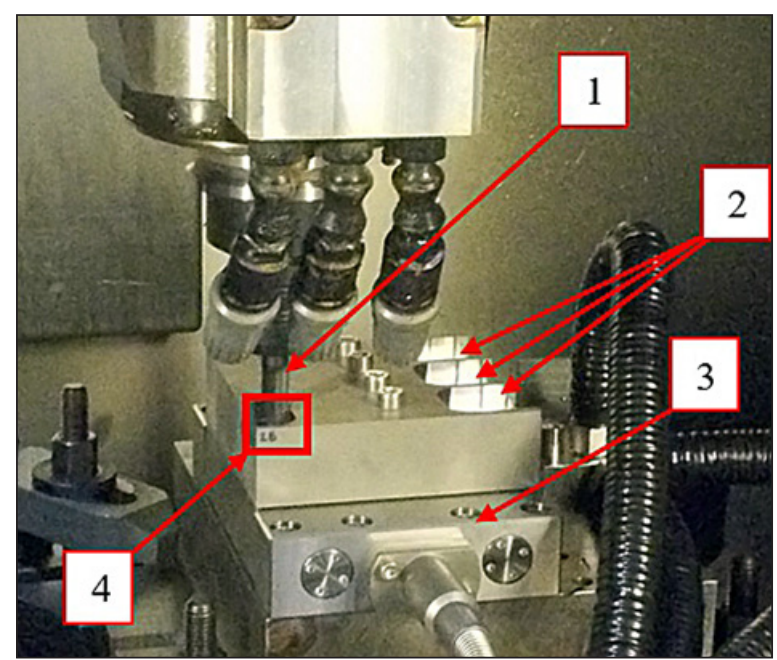

Fig. 6. Experimental setup, where: 1 - cutter; 2 - made grooves, 3 - piezoelectric force meter (holder); 4 - temperature measurement area 
5697A data activating devices and DynoWare $2825 \mathrm{D}$ software for the analytical data. The cutting force was defined as the average value of the force from the measuring section equal to 5 revolutions of the tool at the local apogee. The cutting temperature (Tc) measurements were carried out using a FLIR p620 infrared camera (emissivity factor $\varepsilon=0.80$, measuring resolution $640 \times 480$ pixels), the analyses were performed in the FLIR Tool software. The cutting temperature was defined as the maximum temperature recorded on the tool. Measurements were repeated 5 times for each type of milling. Figures 7, 8, 9, 10 shows all measurement results.

The lowest values of temperatures, roughness $\mathrm{Ra}$, Rt and waviness Wa, Wt were obtained using the type B trochoidal path (Fig. 7, 8). Lower values describing the geometric structure of the surface result

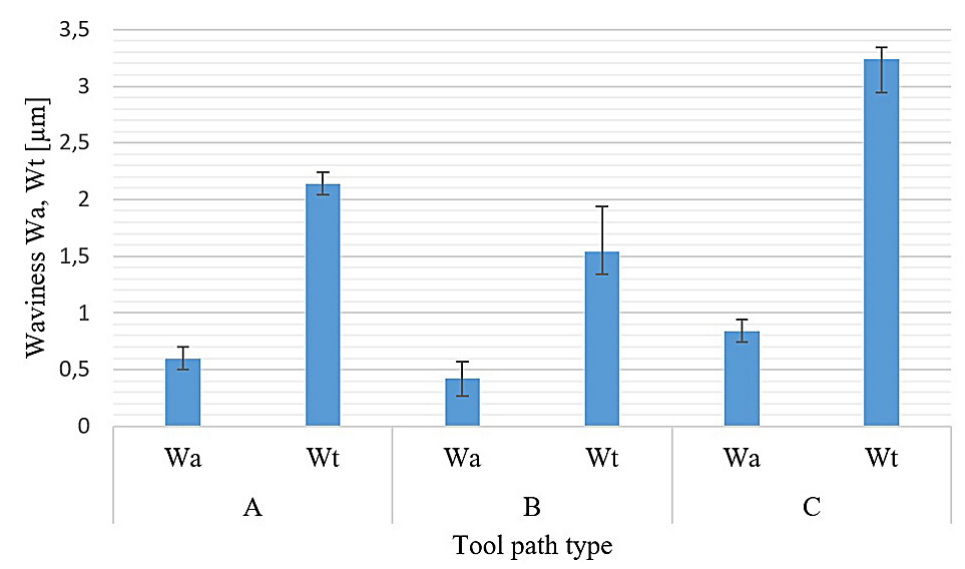

Fig. 7. Influence of trochoidal tool path type on waviness Wa and Wt

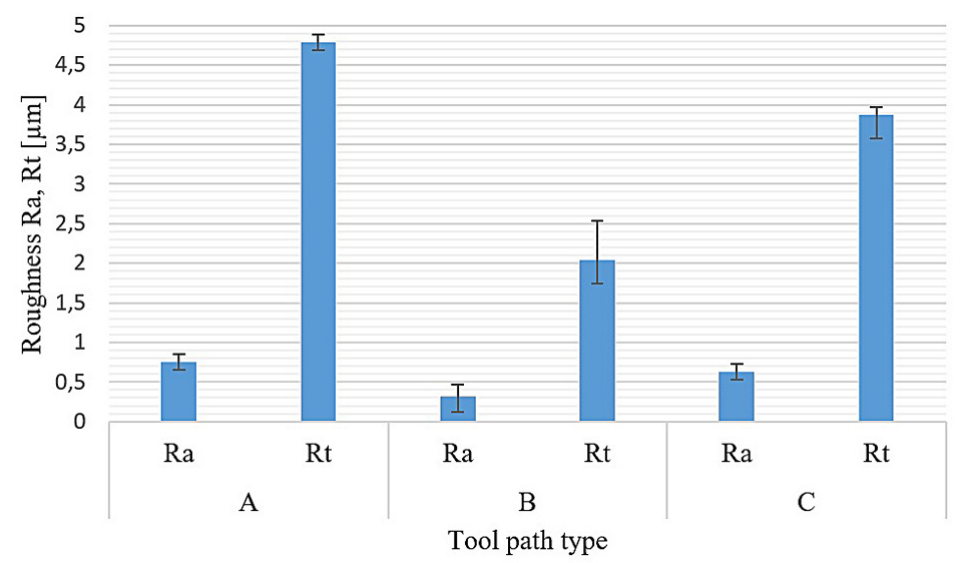

Fig. 8. Influence of trochoidal tool path type on roughness Ra and Rt

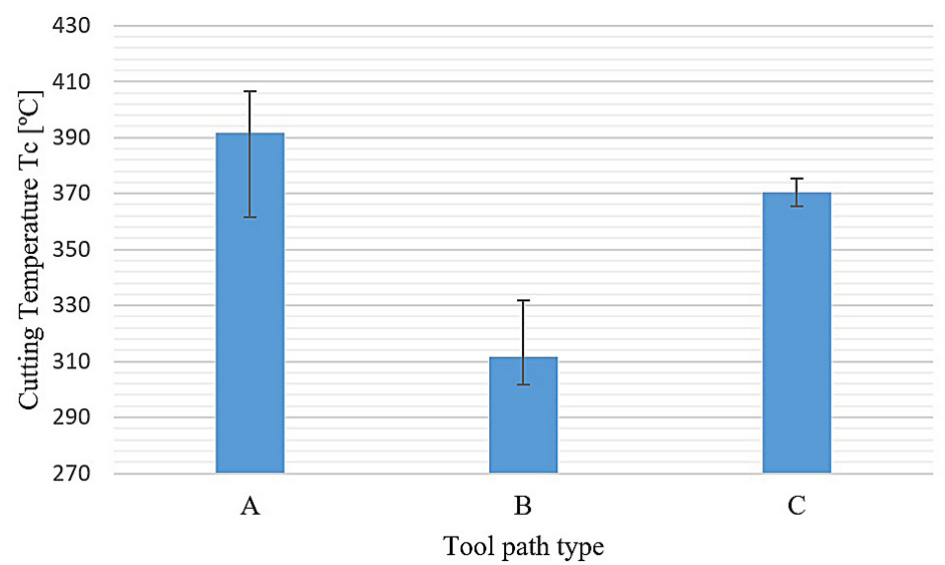

Fig. 9. Influence of trochoidal tool path type on cutting temperature $\mathrm{Tc}$ 


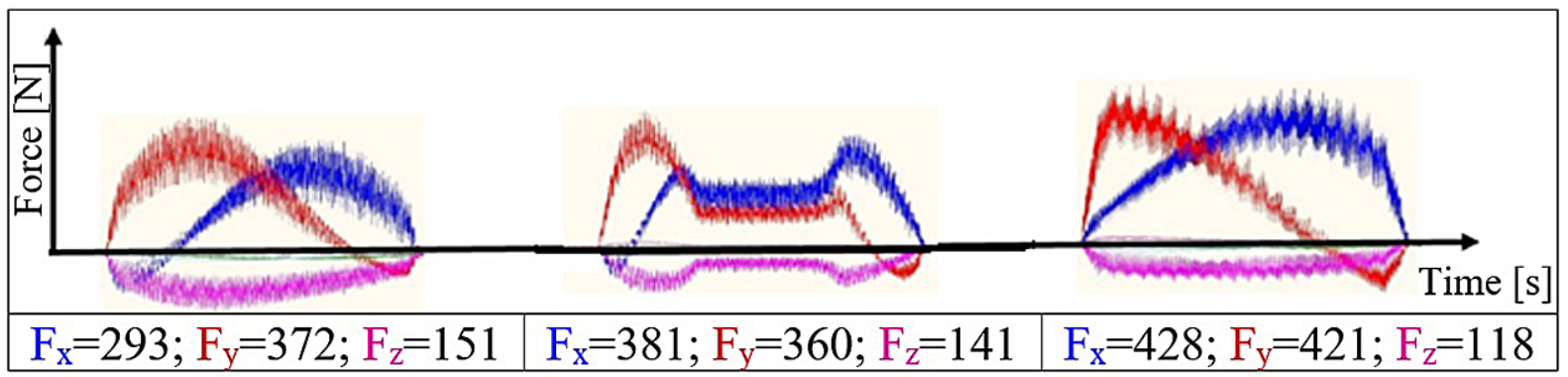

Fig. 10. Influence of trochoidal tool path type on cutting force: $F_{x}, F_{y}, F_{z}$

from the path generation method. The step over of the trochoid which occurs on both walls of the created groove causes surface smoothing. However, this results in an adverse rapid increase in the cutting forces (Fig. 10). Small circular arcs and a straight forming line have a positive effect on the cooling capabilities of the cutting edge, owing to which it is possible to reduce the cutting temperature using path B by nearly $20 \%$ compared to the type $\mathrm{C}$ path and $27 \%$ compared to the type A path (Fig. 9).

\section{CONCLUSION}

The type of trochoidal path significantly affects the final effects of the process. The presented machining with technological parameters recommended by the tool manufacturer during trochoid milling is not always possible. Complications can occur during circular movements of the tool following the setpoint trajectory. The milling machine may not reach the programmed parameters to accelerate the drives lead screw because the tool path is too short. The smaller the radius of the arcs forming the tool movement trajectories, the lower the feed rate values can become for the $\mathrm{CNC}$ milling machine in curvilinear movements.

An additional factor influencing the implementation of movements is the way of interpreting the subsequent tool positions. This is related to the generation of code through straight lines, arcs or points between moves. Therefore, the type of the generated trochoidal tool movement trajectory significantly affects the final effects of machining:

1. For accurate machining (end milling) it is recommended to use the type B path that allows obtaining the lowest values of the Ra, Rz, Wa, and Wt parameters (compared to the $\mathrm{A}$ and $\mathrm{C}$ paths).

2. When milling the elements with thin bottoms, it is recommended to use the C-type path, because the force values $\mathrm{Fz}$ were the lowest (compared to A and B paths).

3. When milling narrow grooves, it is recommended use either the A or C path type to obtain the highest feed speed possible (compared to the $\mathrm{B}$ path).

4. In order to reduce the costs associated with the $\mathrm{CAD} / \mathrm{CAM}$ software, it is possible to replace the type $\mathrm{C}$ path the with G-Code written path - type A path.

\section{REFERENCES}

1. Bettine F., Ameddah H. and Manna R. A Neural Network Approach for Predicting Kinematic Errors Solutions for Trochoidal Machining in the Matsuura MX-330 Five-Axis Machine. FME Transactions, 46, 2018, 453-462.

2. Deng Q., Rong M., Zezhong C.C. and Zhiyong C. A new approach to generating trochoidal tool paths for effective corner machining. The International Journal of Advanced Manufacturing Technology, 95, 2018, 3001-3012.

3. Heidenhain. User's manual cycle programming iTNC 530, 12, 2008.

4. Ibaraki S., Yamaji I. and Matsubara A. On the removal of critical cutting regions by trochoidal grooving. Precision Engineering, 34(3), 2010, 467-473.

5. Manuel M. and Ciro A.R. Influence of tool path strategy on the cycle time of high-speed milling. Computer-Aided Design, 35, 2003, 395-401.

6. Nam-Seok O., Wan-Sik W., and Choon-Man L. A Study on the Machining Characteristics and Energy Efficiency of Ti-6Al-4V in Laser-Assisted Trochoidal Milling. International Journal of Precision Engineering and Manufacturinggreen Technology, 5(1), 2018, 37-45. 
7. Novak-Marcincin J. Problems of optimal cutting strategy application for cnc milling technology. TMT, 11, 2007, 5-9.

8. Otkur M. and Lazoglu I. Trochoidal milling. International Journal of Machine Tools and Manufacture, 47(9), 2007, 1324-1332.

9. Patil P., Polishetty A., Goldberg M., Littlefair G. and Nomani J. Slot Machining of Ti6Al4V with Trochoidal Milling Technique. Journal of Machine Engineering, 14(4), 2014, 42-54.

10.Pleta A. and Mears L. Cutting Force Investigation of Trochoidal Milling in Nickel-Based Superalloy. Procedia Manufacturing, 5, 2016, 1348-1356.

11.Pleta A., Niaki F. A. and Mears L. A Comparative Study on the Cutting Force Coefficient Identification between Trochoidal and Slot Milling. Procedia Manufacturing, 26, 2018, 570-579.

12. Szaloki I., Csuka S. and Sipos S. New Test Results in Cycloid-Forming Trochoidal Milling. Acta Polytechnica Hungarica, 11, 2014, 215-228.

13.Szaloki I., Csuka S., Sipos S. and Csesznok S. Can trochoidal milling be ideal? International
Manufacturing Conference, 12, 2012, 14-16.

14.Waszczuk K., Karolczak P., Wiśniewska M. and Kowalski M. Influence of the path type on selected technological effects in the trochoidal milling. Advances in Science and Technology Research Journal, 11(1), 2017, 147-153.

15. Waszczuk K., Skowronek H., Karolczak P., Kowalski M. and Kołodziej M. Influence of the Trochoidal Tool Path on Quality Surface of Groove Walls. Advances in Science and Technology Research Journal, 13 (3), 2019, 38-42.

16. Yunching H. and James H.O. NC Milling Error Assessment and Tool PathCorrection. Mechanical Engineering, 7, 1994, 287-294.

17.Zagórski I., Kulisz M., Kłonica M. and Matuszak J. Trochoidal Milling and Neural Networks Simulation of Magnesium Alloys. Materials, 12(13), 2019, 2070.

18.Zaleski K., Matuszak J. and Zyśko A. Highly efficient milling on the example of selected machining strategies. Advances in Science and Technology Research Journal, 14(1), 2020, 167-177. 